\title{
DESIGNING BENEFIT RULES FOR FLEXIBLE RETIREMENT WITH OR WITHOUT REDISTRIBUTION
}

\author{
ANDRÁS SIMONOVITS \\ CESIFO WORKING PAPER NO. 1370 \\ CATEgORY 1: Public FinANCE \\ DECEMBER 2004
}

PRESENTED AT THE CESIFO/DELTA CONFERENCE ON STRATEGIES FOR REFORMING

PENSION SCHEMES, NOVEMBER 2004
An electronic version of the paper may be downloaded
- from the SSRN website: http://SSRN.com/abstract $=646044$
- from the CESifo website: www. CESifo.de




\title{
DESIGNING BENEFIT RULES FOR FLEXIBLE RETIREMENT WITH OR WITHOUT REDISTRIBUTION
}

\begin{abstract}
The traditional approach to flexible retirement (e.g. NDC) neglects the impact of asymmetric information on actuarial fairness (neutrality). The mechanism design approach (e.g. Diamond, 2003) gives up the requirement of neutrality and looks for a redistributive second-best benefit-retirement-age schedule. Trying to combine the two approaches, the present paper determines the neutral (redistribution-free) second-best solution. This neutral solution is, however, often Pareto-dominated by the redistributive one.
\end{abstract}

JEL Code: D82, D91, H55.

Keywords: flexible retirement, asymmetric information, actuarial fairness (neutrality), mechanism design.

\author{
András Simonovits \\ Budapest University of Technology and Business \\ Budaörsi út 45 \\ Budapest \\ Hungary \\ simonov@econ.core.hu
}

An earlier version of this paper was presented at a CESifo Conference on Strategies for Reforming Pension Schemes, 5-6 November, 2004, Munich, Germany. Since this paper is a (self-contained) sequel to Eső and Simonovits (2002), my debt to Péter Eső is obvious. I express my gratitude to Peter Diamond, Theijs Knaap, Pierre Pestieau, Ákos Valentinyi and János Vincze for their valuable comments. I also acknowledge the financial support of the Hungarian Science Fund OTKA T046175 and the CESifo. 


\section{Introduction}

Increasing life expectancy notwithstanding, people retire earlier nowadays than they did decades ago. A common explanation for this phenomenon is that pension benefit rules are poorly designed in many countries (e.g. Gruber and Wise, eds., 1999), which, among other things, endangers the sustainability of social security systems. It is therefore an important social task to improve pension benefit rules so that social security systems remain feasible (by, for example, increasing retirement age), while other goals, such as insurance, fairness, and the accommodation of heterogeneous individual characteristics, are also attained.

Most of the literature assumed that the government and the individuals have the same information regarding life expectancies, and only the individuals' disutilities of labor are not known to the government (asymmetric information). Then there is a plausible benefit rule, called actuarially fair in the literature: pay a life annuity equaling to the ratio of the lifetime contribution to the remaining life expectancy. Under this benefit rule, workers, who prefer leisure more, retire earlier and receive a lower life annuity corresponding to their lower lifetime contributions and their longer remaining life expectancies.

Fair systems have recently been introduced in several European countries (Sweden, Italy and Poland) under the name notionally defined contribution system (for short, NDC). (For certain technical problems of NDC, see Valdés-Prieto, 2000.)

But individuals differ not only in their labor disutilities but their life expectancies as well. And there is a strong positive relationship between the individual life expectancy and the individual length of employment - those living longer also work longer. This positive correlation is established empirically by Waldron (2001). There is also direct evidence that people can predict their own life expectancies quite well (Smith et al., 2001). As a result, under such circumstances, not only actuarial fairness but even the aggregate balance between contributions and benefits is destroyed (Simonovits, 2003). To avoid any confusion, we shall speak of a neutral scheme if the expected benefit is equal to the contribution for any type, and add the adjective traditional to the so-called fair systems.

Since the publication of Mirrlees' (1971) seminal paper on optimal income taxation, mechanism design has been providing a tool for solving such problems. In our case, the design determines the optimal flexible retirement rules under the assumption that individuals have private information. The government's goal is to design a pension system (a payroll tax or contribution and a function relating benefits to retirement age), which maximizes a social welfare function and satisfies a social budget constraint. Since individuals with different characteristics optimize their retirement ages conditional on the benefit function, the government must also take into account incentive-compatibility constraints: no type wants to choose a contract designed for another type.

In the pension literature, it was Diamond and Mirrlees (1978) who first studied mechanism design problems, namely concerning disability benefits. It was much later that Fabel (1994), Diamond (2003), Eső and Simonovits (2002), Simonovits (2003) and Sheshinski (2004) considered old-age retirement with heterogeneity in individual life expectancies or disutility of labor. The main contribution of this approach to the existing literature on pension system reforms is to extend the analysis of optimal pension benefit rules in an important new direction, by assuming that individuals have private 
information regarding their life expectancies or disutilities.

Here I shall only discuss Eső and Simonovits (2002). It is a multicohort model, where individuals or types only differ in life expectancies, which are positive integers: $t=$ $S, \ldots, T$. Using the standard techniques of mechanism design, we determined the firstand second-best optimal benefit-retirement age functions. (In the first-best solution, the information is symmetric and the individuals obey the government's decisions. In the second-best solution, the information is asymmetric and the individuals' private interests should be taken into account in the design). The equations, that determine the optimal second-best benefit rule, are analytically derived. This benefit rule appears to be very much different from the traditional fair schedule (which would be acceptable if individuals differed in their disutilities of labor, but not in their life expectancies). Similarly to the traditional rule, the socially optimal (and incentive compatible) benefit rule leads to a redistribution from individuals with shorter life expectancies to individuals with longer life expectancies, though the redistribution is dampened. The properties of the optimal benefit rule depend on the shape of the social welfare function: more egalitarian social objectives lead to more flexible benefit rules. For the utilitarian social welfare function, (defined as the weighted sum of the lifetime utilities) we have obtained a very simple though paradoxical result: the first- and the second-best solutions are identical, every type receives the same periodic benefit and retires at the same age. Notwithstanding the rigidity of such a 'flexible' retirement scheme, it will be used as a benchmark in the present paper as well (Figures 1 and 2).

The assumption of redistribution among various types is a natural assumption in the optimal taxation literature but is in sharp contrast with some other fields of information economics. For example, in the basic model of optimal insurance under asymmetric information (Rothschild and Stiglitz, 1976), both types of the insured have a zero balance (neutrality), and the inefficiency of the second-best optimum appears in the partial insurance of the low-risk type. Here the participation is not mandatory and the market competition ensures that the insurers' profits be zero.

The present paper combines the pension design methodology with the neutrality requirement. Apart from a benchmark model in Section 5, I restrict the retirement rules to (actuarially) neutral ones. There is no need to assume a social welfare function. Following Rothschild and Stiglitz, we could even assume that there are plenty of competing insurance agencies selling optimal pension policies to the workers. But we retain the mandatory character of the pension system and charge the government with the design of a socially optimal neutral system.

As a by-product, the redistributive model of Eső and Simonovits is simplified, because the retirement age of any type is determined by his benefit, reducing the dimension of the problem from 2 to 1.

The main findings are as follows: (i) There exists a neutral first-best benefitretirement age rule: every type receives the same periodic benefit and his retirement age is proportional to his (adult) life expectancy. (This solution was called the autarkic first-best in Eső and Simonovits and it could also be called optimum under symmetric information.) (ii) There exists a neutral second-best benefit-retirement age schedule, which is constrained Pareto-optimal among the incentive-compatible neutral rules. (iii) Under certain technical assumptions, the neutral second-best retirement age of the longest-lived is oversensitive to the life expectancies, i.e. the difference between the re- 
tirement ages of the first and the second longest-lived types is larger than the difference between their life expectancies.

(iv) To formulate the major result, we must introduce a social welfare function and a redistributive second-best solution (Eső and Simonovits, 2002). For the two-type case, under related technical assumptions, the neutral second-best solution is not only welfare inferior to but Pareto-dominated by the redistributive second-best solution: the neutral solution is inefficient. We have also numerical examples for multitype models, where the same relation holds. A heuristic explanation is as follows: To deter the longestlived type from pretending to be next-to-longest-lived, the neutral second-best must give the latter a too low benefit, even if this implies an excessively low retirement age as well. The neutral solution is Pareto-inferior to the redistributive solution, because in the latter the type-specific retirement ages and benefits are much less diverse and on average much higher than in the former. (In a variant of the basic model, Rothschild and Stiglitz have found similar results.)

While concentrating on the heterogeneity in life expectancies and labor disutilities, all these studies have neglected a third characteristic: earnings. Obviously, in most (though not in all) systems, individual monthly earnings are observable by the government and are strongly correlated with the foregoing characteristics. Incidentally, the main criticism of World Bank (1994) against the proportional pension systems is that they achieve a perverse redistribution from the expectedly long-lived rich to the expectedly short-lived poor. This difficult issue will be discussed in another study.

The structure of the paper is as follows: Section 2 presents the model of a neutral pension system. Sections 3 and 4 derive the first-best and the second-best solutions, respectively. Section 5 compares the neutral second-best solution with the redistributive one. Section 6 concludes.

\section{The model}

We analyze the following problem. There is a (stationary) population of individuals who have private information regarding their life expectancies (a generic life expectancy is denoted by $t$, calculated from starting the careers). Every individual enters the labor market at age 0 , and produces 1 unit of goods per year while he is active, 0 unit when he is inactive (retired or dead). (Therefore, in our model, the retirement age and length of employment are the same.) As is usual in models of old-age pension systems, we assume that workers cannot privately save for retirement. (For an exception, see Diamond and Mirrlees, 2005.)

The pension systems we consider will be realistic in the following aspects. The first ingredient of a pension scheme is a yearly social security payroll tax, $\tau<1$, which is levied on active workers (we assume away other taxes). The tax rate is fixed in this model. When a worker retires (say, at age $R$ ), he stops producing goods and paying the tax, and receives a yearly retirement benefit, $b>0$, until he dies. In the traditional literature, it is customary to depict the design as the benefit-retirement age function $b(R)$. Following the optimal design methodology, however, here we shall work with a parametric solution $\left(b_{t}, R_{t}\right)$, where $t$ is the generic life expectancy. We require that the pension system be neutral (for any type, the expected benefit payments cannot exceed 
the amount of social security taxes paid in). We do not allow the pension system to cut off or reduce the benefits of individuals over time, or give out the benefit as a lump-sum transfer at retirement.

We assume that the retirement age of a worker with the longest life expectancy is less than the lower bound on the distribution of $t: R_{T}<S_{\min }$. (This is a reasonable assumption for old-age pension. Without this assumption, the death of the shortest-lived persons would provide new information on the life expectancies of the still working types to the government, even if there were no uncertainty in individual life expectancies.)

An individual's lifetime utility, $v$, is the sum of his total utilities when active and when retired. If a worker of type $t$ retires at age $R$, then he receives utility or felicity $u=u(1-\tau)$ for $R$ years and $w(b)$ for $(t-R)$ years, and the (expected) lifetime utility is given by the linear combination:

$$
v_{t}=R u+(t-R) w(b) .
$$

Note that the random lifetime utility, due to random life span $\mathbf{t}$, is

$$
\mathbf{v}_{\mathbf{t}}=R u+(\mathbf{t}-R) w(b),
$$

and $b$ and $R$ only depend on the life expectancy $t$ but not on $\mathbf{t}$, therefore the expected value of $\mathbf{v}_{\mathbf{t}}$ is provided by (1). The same is true for the type-specific budget constraints of (3) below.

The individual's preference for leisure is reflected in that $u(\cdot)$ and $w(\cdot)$ are different functions. We only make a single technical restriction on $u$ and $w$ :

$$
w(0)-w^{\prime}(0) \tau<u<w(1)-w^{\prime}(1)(\tau+1) .
$$

This assumption is needed to have a first-best optimum in the interval $0<b<1$ (cf. Theorem 1 below) and it is quite mild. (It could be even further relaxed if we did not require $b<1$, but this inequality will be needed.) We shall strengthen it and assume below that $w(0)<u$ (even $w(0)=-\infty)$, therefore the lower bound is innocent. Turning to the upper bound, and calling $\varepsilon=w(1-\tau)-u$ the disutility of labor at the tax rate $\tau$, and using the concavity of $v_{t}, \varepsilon+u=w(1-\tau)<w(1)-w^{\prime}(1)(1-\tau)$, i.e. $u=w(1-\tau)-\varepsilon<w(1)-w^{\prime}(1)(1-\tau)-\varepsilon<w(1)-w^{\prime}(1)(\tau+1)$ holds if $2 w^{\prime}(1) \tau<\varepsilon$ is valid, i.e. the labor disutility $\varepsilon$ is sufficiently large with respect to the tax rate $\tau$.

As was mentioned, we shall assume neutrality, i.e. the equality of lifetime contributions and expected lifetime benefits:

$$
\tau R=b(t-R) \quad \text { or } \quad b=\frac{\tau R}{t-R} \quad \text { or } \quad R=\frac{b}{\tau+b} t .
$$

We shall often distinguish the neutral solution by a tilde. Substituting (3) into (1),

$$
\tilde{v}_{t}=t \varphi(b), \quad \text { where } \quad \varphi(b)=\frac{u b+w(b) \tau}{\tau+b} .
$$

We consider a discrete-type model. Types (life expectancies $t$ ) range from $S$ to $T$ (all integers). To avoid triviality, we assume that there are at least two types, i.e. $S<T$. Let $f_{t}$ be the relative frequency of individuals with life expectancy $t: f_{S}, f_{T}>0$ and $\sum_{t=S}^{T} f_{t}=1$. 


\section{First-best solution}

In this section, we derive the optimal benefit-retirement age schedule under the assumption that every worker's life expectancy is commonly observable and the individuals retire at type-specific ages optimizing their lifetime utilities. This result will serve as a benchmark for the optimum under asymmetric information, which is the subject of the next section.

We shall assume that the government designs a socially optimal, mandatory pension system. It offers contracts $\left(b_{t}, R_{t}\right)$, maximizing the type-specific lifetime utility $\tilde{v}_{t}$ subject to zero-balance constraints and fixing the values of other $\tilde{v}_{t^{\prime}} \mathrm{s}, t^{\prime} \neq t, t=S, \ldots, T$.

We call this problem the neutral first-best problem. (Those readers who identify first-best with an optimum, where only physical constraints are taken into account, may call this problem as the optimization under symmetric information.) Denoting the corresponding solution by ${ }^{*}$, we obtain

Theorem 1. a) There exists a unique neutral first-best schedule $\left\{b_{t}^{*}, R_{t}^{*}\right\}_{t=S}^{T}$, where the benefit is invariant with respect to the life expectancy: $b_{t}^{*} \equiv b^{*}$, satisfying

$$
u-w\left(b^{*}\right)+w^{\prime}\left(b^{*}\right)\left(\tau+b^{*}\right)=0 .
$$

b) The neutral first-best retirement age is proportional to the type's life expectancy:

$$
R_{t}^{*}=\frac{b^{*} t}{\tau+b^{*}}
$$

Remark. Condition (2) guarantees the existence of a positive benefit, satisfying (5), implying $u<w\left(b^{*}\right)$. Then the solution is unique because the derivative of the LHS of (5) is negative.

Proof. The individual maximization problems are independent of each other. By (4), the first-order conditions are the same for each type:

$$
\varphi^{\prime}(b)=\frac{u-w(b)+w^{\prime}(b)(\tau+b)}{(\tau+b)^{2}} \tau=0
$$

implying (5). (3) implies (6).

For simplicity, we may assume that $u(x) \equiv w(x)-\varepsilon, \varepsilon>0$, where $\varepsilon$ is a constant disutility of labor. Then in the first-best case, there exists an individually optimal tax rate, namely $\tau^{*}=1-b^{*}\left(\tau^{*}\right)$ : the worker's consumption is equal to the pensioner's. (This is an unwanted consequence of our assumption: the worker's and the pensioner's felicity functions only differ in an additive constant $\varepsilon$.)

\section{Second-best solution}

We return now to the model's original informational assumption and assume that individuals have private information regarding their life expectancies, and only the distribution of these data is commonly known. It is obvious that under such circumstances 
rules (5)-(6) cannot be used, because everybody except type $S$ will underreport his life expectancy. Therefore the optimal benefit-retirement age schedule will have to satisfy incentive-compatibility (for short, IC) constraints.

Incentive compatibility of $\left\{\bar{b}_{t}, \bar{R}_{t}\right\}_{t=S}^{T}$ means that every type $t$ prefers to choose $\bar{b}_{t}$ from the schedule, while $\bar{R}_{t}$ is determined by (3). It is enough to consider downward adjacent IC constraints: type $t+1$ prefers to retire at $\bar{R}_{t+1}$ with a life annuity $\bar{b}_{t+1}$, rather than to retire earlier, at $\bar{R}_{t}$ with a reduced life annuity $\bar{b}_{t}$ and draw it for longer than expected by the government. (The upward adjacent IC constraints are automatically satisfied, because nobody needs pretend that he expectedly lives longer than is his actual life expectancy!) In formula,

$$
v_{t+1} \geq\left[u-w\left(b_{t}\right)\right] R_{t}+w\left(b_{t}\right)(t+1)=v_{t}+w\left(b_{t}\right),
$$

i.e.

$$
v_{t+1} \geq v_{t}+w\left(b_{t}\right), \quad \text { for } \quad t=S, \ldots, T-1 .
$$

It is easy to show that $b_{t}<b_{t+1}$ (from which it also follows that $R_{t}<R_{t+1}$ ).

The problem of optimum now becomes finding a series of benefits $\bar{b}_{t}$ and the corresponding retirement ages $\bar{R}_{t}=\bar{b}_{t} t /\left(\tau+\bar{b}_{t}\right),(t=S, \ldots, T)$ which are strictly constrained Pareto-optimal: there are no other $b_{t}$ s for which $\tilde{v}_{t} \geq \bar{v}_{t}$; subject to

$$
\tilde{v}_{t+1} \geq \tilde{v}_{t}+w\left(b_{t}\right), \quad t=S, \ldots, T-1 .
$$

We will call this problem the neutral second-best problem and analyze its solution in this Section.

We reiterate that the neutral first-best solution does not satisfy the IC conditions: for the longer-lived types, it is worth pretending they are shorter-lived; they can retire earlier without receiving lower benefit.

Inserting $\tilde{v}_{t}=t \varphi\left(b_{t}\right)$ into (7), we have the Pareto-optimality problem subject to

$$
(t+1) \varphi\left(b_{t+1}\right)-t \varphi\left(b_{t}\right)-w\left(b_{t}\right) \geq 0, \quad \text { for } \quad t=S, \ldots, T-1 .
$$

We strengthen the LHS of assumption (2) as follows: people marginally prefer working for a net earning $1-\tau$ to be retired at zero benefit: $u>w(0)$. Corollary: there exists a solution to $w\left(b_{\mathrm{o}}\right)=u$, i.e. a positive benefit $b_{\mathrm{o}}$ such that the corresponding pensioner's felicity is equal to that of the worker.

An elementary observation yields

Theorem 2. There exists a unique neutral second-best solution, where the benefits $\left\{\bar{b}_{t}\right\}$ satisfy the following implicit difference equation:

$$
(t+1) \varphi\left(\bar{b}_{t+1}\right)-t \varphi\left(\bar{b}_{t}\right)-w\left(\bar{b}_{t}\right)=0, \quad \text { for } \quad t=S, \ldots, T-1,
$$

with end-value $\bar{b}_{T}=b^{*}$. Moreover, the benefits increase with life expectancy: $\bar{b}_{T}>$ $\bar{b}_{T-1}>\cdots>\bar{b}_{S}>b_{\mathrm{o}}$.

Remarks. 1. There is nothing peculiar in the fact that the highest-risk type can achieve his first-best. It is much less usual, however, that the neutral second-best solution is not only constrained Pareto-optimal, but it dominates the other feasible solutions in the following very strong sense: let $t_{*}$ be any integer between $S$ and $T$. Even dropping the types $t=t_{*}+1, \ldots, T$, if $b_{t_{*}}<\bar{b}_{t_{*}}$, then $b_{t}<\bar{b}_{t}$ for $t=S, \ldots, t_{*}-1$.

2. It is a peculiar feature of this solution that adding one more, shortest-lived cohort $(S-1)$ to the population, the new optimal schedule contains the old: $\bar{b}_{t}$ is independent of $\bar{b}_{S-1}$. 
Proof. Because $\varphi$ is the weighted average of $w(b)$ and $u[(4)], \varphi\left(b_{\mathrm{o}}\right)=w\left(b_{\mathrm{o}}\right)$. Therefore $b_{t} \equiv b_{\mathrm{o}}$ satisfies $\left(8^{\prime}\right)$, the set of feasible solutions is not empty. Because $\varphi(\cdot)$ is increasing in the interval $\left[b_{\mathrm{o}}, b^{*}\right]$, each $\bar{b}_{t}$ can be increased to its conditional maximum, determined by its successor $\bar{b}_{t+1}$ via $\left(8^{\prime}\right)$. Since $\bar{b}_{T}$ has no successor, its unconstrained optimum, $b^{*}$ can be chosen.

By mathematical induction, $\bar{b}_{T}>\bar{b}_{T-1}>\cdots>\bar{b}_{S}>b_{\mathrm{o}}$.

In the second-best case, we can determine the solution step-by-step, in reversed order. To simplify the calculations, we shall assume that $u(x) \equiv w(x)-\varepsilon$, when the tax rate $\tau^{*}=1-b^{*}$ is also first-best (i.e. the worker's consumption is equal to the pensioner's).

To have a feeling for the order of magnitudes, it will be helpful to simulate our findings (Eső and Simonovits, 2002). Assume that from the point of view of the government, the individuals' life expectancies (starting from entering the workforce at age 20) are between $S=49$ and $T=59$ years. Let the pensioner's felicity function be of CRRAtype, $w(x)=x^{\sigma} / \sigma+\theta$, where $\theta$ is large enough to ensure that $u(x) \equiv w(x)-\varepsilon>0$, (otherwise $v_{t+1}>v_{t}$ may not hold); $1-\sigma$ being the coefficient of relative risk aversion. We set $\theta=1, \sigma=-.5$ and $\varepsilon=1.398$. The neutral first-best benefit, $b^{*}=.8$, hence $\tau^{*}=.2$. It is worth displaying the numerical characteristics of the second-best solution in Figure 1 and Table 1. The content of the last column will be explained later.

Table 1. Characteristics of the neutral (and the redistributive) second-best solution

\begin{tabular}{|c|c|c|c|c|}
\hline $\begin{array}{l}\text { Life } \\
\text { expectancy } \\
t\end{array}$ & $\begin{array}{l}\text { benefit } \\
\bar{b}_{t}\end{array}$ & $\begin{array}{l}\mathrm{N} \text { e u t r a l } \\
\text { retirement } \\
\text { age (yrs) } \\
\bar{R}_{t}\end{array}$ & $\begin{array}{l}\text { lifetime } \\
\text { utility } \\
\tilde{v}_{t}\end{array}$ & $\begin{array}{l}\text { Redistributive } \\
\text { lifetime } \\
\text { utility } \\
\hat{v}_{t}\end{array}$ \\
\hline 49 & 0.424 & 33.3 & 31.7 & 30.9 \\
\hline 50 & 0.433 & 34.2 & 32.7 & 32.8 \\
\hline 51 & 0.443 & 35.1 & 33.7 & 34.7 \\
\hline 52 & 0.455 & 36.1 & 34.8 & 36.5 \\
\hline 53 & 0.468 & 37.1 & 36.0 & 38.4 \\
\hline 54 & 0.484 & 38.2 & 37.2 & 40.3 \\
\hline 55 & 0.504 & 39.4 & 38.4 & 42.1 \\
\hline 56 & 0.528 & 40.6 & 39.7 & 44.0 \\
\hline 57 & 0.562 & 42.0 & 41.0 & 45.9 \\
\hline 58 & 0.614 & 43.7 & 42.4 & 47.7 \\
\hline 59 & 0.800 & 47.2 & 44.0 & 49.6 \\
\hline
\end{tabular}

Figure 1

The most surprising feature of the neutral second-best solution is that the longestlived type must work 3.5 years longer than the next type (just because he lives one year longer). On the other hand, he receives a much higher benefit than his neighbor does: $80 \%$ vs $61.4 \%$. The other types' (retirement age, benefit) pairs seem to be acceptable, although the greater than one-to-one reduction of retirement age and life expectancy is excessive for types $t=52, \ldots, 59$. 
Before formulating our next theorem, we must define the degree of discretization. Working with discrete types, we partition the maximal life expectancy into intervals of equal size (e.g. year or quarter or month, etc.) and do not distinguish between workers with life expectancies lying in the same interval. Assume that the maximal life expectancy is given in terms of the interval length. The degree of discretization or the relative coarseness of the model is now defined as the reciprocal of the maximal life expectancy: $\xi=1 / T$. We shall give a condition concerning the oversensitivity of the retirement age on the longest life expectancy.

Theorem 3. Assume that $v(0)=-\infty$. In the neutral second-best solution, the highest retirement age is oversensitive to life expectancy, i.e. the difference between the two highest retirement ages is greater than unity: $\bar{R}_{T}-\bar{R}_{T-1}>1$ if and only if the degree of discretization is low enough: $\xi=1 / T<\xi_{*}$, where the scalar $\xi_{*}$ is determined by

$$
\xi_{*} u+\left(1-b^{*}\right) w\left(b^{*}\right)=\left(1-b^{*}+\xi_{*}\right) w\left(b^{*}-\xi_{*}\right) .
$$

Remark. Translating our technical condition into economics: the relative distance between the two longest life expectancies should be sufficiently small.

Proof. We want to demonstrate that $\bar{R}_{T-1}<R_{*}=\bar{R}_{T}-1$. Using $\xi=1 / T$ and $\bar{R}_{T}=b^{*} T$, this is equivalent to

$$
\bar{b}_{T-1}<b_{*}=\frac{\tau R_{*}}{T-1-R_{*}}=\frac{\tau\left(b^{*} T-1\right)}{T-b^{*} T}=b^{*}-\xi .
$$

By $\left(8^{\prime}\right)$ and $(10)$,

$$
\varphi\left(b^{*}\right)=(1-\xi) \varphi\left(\bar{b}_{T-1}\right)+\xi w\left(\bar{b}_{T-1}\right)<(1-\xi) \varphi\left(b_{*}\right)+\xi w\left(b_{*}\right) .
$$

Inserting (4) into both sides of the inequality, and using $1-b^{*}+b_{*}=1-\xi$ yields

$$
u \xi+w\left(b^{*}\right)\left(1-b^{*}\right)<w\left(b^{*}-\xi\right)\left(1-b^{*}+\xi\right) .
$$

Finally, we shall demonstrate that there exists a feasible solution to (9), implying (11) for $0<\xi<\xi_{*}$. Let $F(\xi)=\left(1-b^{*}+\xi\right) w\left(b^{*}-\xi\right)-\xi u-\left(1-b^{*}\right) w\left(b^{*}\right)$. Writing $\tau=1-b^{*}$ and $\varepsilon=u-w\left(b^{*}\right), F(\xi)=(\tau+\xi) w\left(b^{*}-\xi\right)-\xi\left[w\left(b^{*}\right)-\varepsilon\right]-\tau w\left(b^{*}\right) . F(0)=0$, $F(1-\tau)=-\infty,(w(0)=-\infty) F^{\prime}(\xi)=w\left(b^{*}\right)+(\tau+\xi) w^{\prime}\left(b^{*}-\xi\right)-w\left(b^{*}\right)+\varepsilon$, i.e. $F^{\prime}(0)=\tau w^{\prime}\left(b^{*}\right)+\varepsilon>0$. Thus there exists at least one $\xi_{*}$, for which (9) and (11) hold.

In our numerical example, $\xi_{*}=0.4$, i.e. for any degree of discretization less than $1 / 3$ (i.e. $T \geq 3$ ), the longest retirement age is oversensitive to the life expectancy.

Before generalizing Theorem 3, we introduce the concept of minmax ratio of the minimal and maximal life expectancies $S / T$. It is noteworthy that if the degree of discretization is high, then the minmax ratio is low, but its reverse need not be true. Furthermore, for two-type models $(S=T-1)$, the sum of the degree of discretization and the minmax ratio is equal to 1.

On the basis of our numerical experiment reported above, we risk

Conjecture 1. If the assumptions of Theorem 3 hold and the minmax ratio $S / T$ is sufficiently close to 1 , then the neutral second-best retirement age of each type is oversensitive: $\bar{R}_{t-1}<\bar{R}_{t}-1$ for $t=S+1, \ldots, T$.

Remark. Note that $\bar{R}_{t-1}<\bar{R}_{t}-1$ cannot hold for all $t$ s with $S<T-\bar{R}_{T}$, since $0<\bar{R}_{t}<t$. Nevertheless, it holds for the longest-lived 7 out of 10 types in Table 1 . 


\section{Comparison with the redistributive solution}

In this Section, we shall demonstrate that the neutral second-best solution is frequently socially inefficient: it is often dominated by a redistributive second-best solution, analyzed in Eső and Simonovits (2002). In the latter, the benefit $b_{t}$ does not determine the retirement age $R_{t}$, redistribution among different types is allowed. As a result, we must define the lifetime balance of type $t: z_{t}=\tau R_{t}-b_{t}\left(t-R_{t}\right)$. Type-specific budget constraints $z_{t}=0(t=S, \ldots, T)$ are replaced by an aggregate balance: $Z=\sum_{t=S}^{T} z_{t} f_{t}=0$. [Note that the average life expectancy is $m=\sum_{t=S}^{T} t f_{t}$ and the traditional benefit is $b(R)=\tau R /(m-R)$, implying $z_{t}=b\left(R_{t}\right)(m-t) \neq 0$ (Simonovits, 2003, Theorem 3).] In contrast to the neutral case, here the government must maximize a social welfare function. The definitions of first- and second-best solutions are otherwise similar to those for the neutral case. Note that the redistributive first-best benefits are also uniform and equal to $b^{*}$. In more detail, the government designs an optimal pension system, $\left\{b_{t}, R_{t}\right\}$, which maximizes an additive concave social welfare function, $V=\sum_{t} \psi\left(v_{t}\right) f_{t}$, where $\psi$ is an increasing and concave function, transforming individual utilities into social ones. Note also that adding up the transformed utilities of individuals with different life expectancies means that we consider the total lifetime utilities of a cohort.

To simplify the exposition, here we confine our attention to the utilitarian welfare function, $V=\sum_{t=S}^{T} v_{t} f_{t}$, and $v_{t}$ is defined in the redistributive formula (1) rather than in the neutral formula (4). It is easy to see that there exists a second-best solution with uniform first-best retirement ages $\hat{R}_{t} \equiv m b^{*} /\left(\tau+b^{*}\right)$ and benefits $\hat{b}_{t} \equiv b^{*}$, where $m$ is the average life expectancy of the cohort (Eső and Simonovits, 2002, Theorems 0 and 1). We shall use this pooling solution as a benchmark, see the two horizontal lines RB and RRA representing $\hat{b}_{t}$ s and $\hat{R}_{t}$ s in Figure 1 above, respectively. (We assume that the life expectancies are uniformly distributed: $f_{t} \equiv 1 /(T-S+1)$.)

It is evident that in the neutral second-best solution, the longest-lived must work much longer than in the redistributive one. (This difference is maximal in the utilitarian case and the reverse is true for the shortest-lived.) Since the benefits are the same in both systems, the longest-lived's lifetime utility is much higher in the redistributive system than in the neutral one.

In the rest of the Section, we are looking for conditions ensuring the Pareto-dominance of the redistributive design over the neutral one: $\tilde{v}_{t}<\hat{v}_{t}, t=S, \ldots, T$.

We shall start with the simplest case, namely when there exists only two types: $S=T-1$. We repeat that the time units need not be years, they may be decades or months or other units. Also, in the two-type model, there is no need to assume that $S$ and $T$ are integers, for example, it is possible that $S=4.9$ and $T=5.9$ decades.

We shall use notation $f_{T-1}=p, 0<p<1$. We shall prove

Theorem 4. In the two-type case: $S=T-1$, the utilitarian redistributive secondbest dominates the neutral second-best if and only if the degree of discretization is low enough: $\xi<\xi_{\mathrm{o}}$, where

$$
\xi_{\mathrm{o}}=\min \left[\frac{\varphi\left(b^{*}\right)-\varphi(\bar{b})}{w\left(b^{*}\right)-\varphi(\bar{b})}, \frac{1}{2}\right]
$$

and $\bar{b}\left(b_{\mathrm{o}}<\bar{b}<b^{*}\right)$ is determined by

$$
w(\bar{b})=p b^{*} u+\left(1-p b^{*}\right) w\left(b^{*}\right) .
$$


Remark. There exists a unique $\bar{b}$ which satisfies (13), because $0<p b^{*}<1$. It is easy to prove that the higher the share $p$ of the shorter-lived in the population, the less is the per capita burden of redistribution, i.e. the closer $\xi_{\text {o }}$ is to $1 / 2$, i.e. the more probable is that Theorem 4 holds.

Proof. Benefit $\bar{b}_{T-1}$ is determined by $\left(8^{\prime}\right)$ for $t=T-1$.

First we demonstrate that $\tilde{v}_{T-1}<\hat{v}_{T-1}$ if and only if $\bar{b}_{T-1}>\bar{b}$. By $\left(8^{\prime}\right), \tilde{v}_{T-1}=$ $T\left[u b^{*}+w\left(b^{*}\right)\left(1-b^{*}\right)\right]-w\left(\bar{b}_{T-1}\right)$ and $\hat{v}_{T-1}=u b^{*} m+w\left(b^{*}\right)\left(T-1-b^{*} m\right)$. After rearrangement, and using $T-m=p, \tilde{v}_{T-1}<\hat{v}_{T-1}$ reduces to

$$
w\left(\bar{b}_{T-1}\right)>p b^{*} u+\left(1-p b^{*}\right) w\left(b^{*}\right) .
$$

By (13), (13') holds if and only if $\bar{b}_{T-1}>\bar{b}$.

Second, we shall show that $\bar{b}_{T-1}>\bar{b}$ is equivalent to $\xi<\xi_{\mathrm{o}}$. Since $\varphi(b)$ is a weighted average of $u$ and $w(b)$, and $u<w(b)$, thus $\varphi(b)<w(b)$. The RHS of $\varphi\left(b^{*}\right)=$ $(1-\xi) \varphi\left(\bar{b}_{T-1}\right)+\xi w\left(\bar{b}_{T-1}\right)$ is a decreasing function of $\xi$, i.e. $\bar{b}_{T-1}$ is a decreasing function of $\xi$.

We have not yet found analytical results for the general, multitype case, where $S \leq T-1, S$ and $T$ are integers again. We only risk

Conjecture 2. If the degree of discretization is low enough: $\xi<\xi_{\mathrm{o}}$ (cf. Theorem 4) and the minmax ratio is sufficiently close to $1: S / T>1-\xi_{\mathrm{o}}$, then the utilitarian redistributive second-best Pareto-dominates the neutral second-best.

The idea of a would-be proof is the following: try to show that the two-type neutral $(S, T)$ solution (denoted by breve) separates the fine neutral and the fine redistributive ones: $\tilde{v}_{t}<\breve{v}_{t}<\hat{v}_{t}$, for $t=S, \ldots, T$, where $\breve{v}_{t}$ is the linear interpolation of $\breve{v}_{S}$ and $\breve{v}_{T}$ :

$$
\breve{v}_{t}=\frac{t-S}{T-S} \breve{v}_{T}+\frac{T-t}{T-S} \breve{v}_{S} .
$$

Returning to simulations, for $p=1 / 2, \xi_{\mathrm{o}}$ in Theorem 4 is quite small, much smaller than the trivial bound $1 / 2$ in (12). The last column of Table 1 contains the lifetime utilities of the utilitarian redistributive solution. Note, that apart from the shortest-lived type, the lifetime utilities in the redistributive system are higher than their counterparts in the neutral solution: see also Figure 2. In other words: the redistributive solution almost Pareto-dominates the neutral solution. By shifting contributions from the shorter-lived into benefits of the longer-lived (amounting to 4 years total earnings in the extreme), in our second-best world, much higher activity is achieved than under the type-specific constraints. For example, in the redistributive second-best, everybody works 43.2 years. Only the longest-lived work much longer in the neutral solution: 47.2 years; while the shortest-lived only work 33.3 years.

Figure 2

A further simulation (not detailed here) shows that increasing the minmax ratio (the minimal life expectancy $S$ rises from 49 to 52 years, while fixing the maximal life expectancy at $T=59$ years) leads to Pareto-improvement over the neutral solution. (Note that although $\tilde{v}_{50}<\hat{v}_{50}$ for $S=49$ and $\tilde{v}_{50}$ is the same for $S=49$ or 50 but $\hat{v}_{50}$ is sensitive to the choice of $S$. Therefore $S=50$ would not guarantee Pareto-dominance.) 
Note that for strictly concave social welfare functions, the conditions of the Paretoimprovements are even milder. In our example, for the social welfare function with $\psi(v)=-1 / v$, the optimal redistributive solution just Pareto-dominates the neutral one: $\hat{v}_{49}=31.7$.

Note that in our simulation of Conjecture $2, \xi_{\mathrm{o}}=0.038$, and for $T=59$ years, it yields $S=57$ years. In fact, as we have seen above, even the value $S=52$ years guarantees the improvement.

\section{Conclusion}

In this paper we have made a step to apply mechanism design to pension benefit rules, in the case, where individuals have private information regarding their own life expectancies and redistribution among different types is excluded. We have characterized the optimal benefit function as the solution of a nonlinear difference function. Both the problem and the simulation are much simpler than in the redistributive model of Eső and Simonovits. A very disquieting feature of the neutral second-best solution is, however, that the "optimal" benefit as well as the retirement age schedule rises very steeply for individuals with sufficiently long life expectancies. Moreover, the neutral second-best solution is often Pareto-dominated by the redistributive counterpart. Neutral second-best is feasible but disadvantageous.

Until now we have fixed the disutility of labor. Varying disutility of labor was discussed by Diamond (2003) and Sheshinski (2004) but for prescribed rather than chosen retirement ages and the type formation was endogenous. Another approach was chosen by Simonovits (2003), where types differred by disutility of labor as well as life expectancy but only linear benefit-retirement age functions were considered. All these approaches have neglected a third dimension, namely wage heterogeneity. Much work needs to be done to have a richer theory than we have now.

\section{References}

DIAMOND, P. (2003): "Taxation, Incomplete Markets and Social Security", Munich Lectures, Cambridge, MA, MIT Press.

DIAMOND, P. and MIRRLEES, J. (1978): "A Model of Social Insurance with Variable Retirement", Journal of Public Economics 10 295-336.

DIAMOND, P. and MIRRLEES, J. (2005): "Social Insurance with Variable Retirement and Private Saving", to appear in Journal of Public Economics.

ESÖ, P. and SIMONOVITS, A. (2002): "Designing Optimal Benefit Rules for Flexible Retirement", Discussion Paper CMS-EMS 1353, Northwestern University, Evanston, IL.

FABEL, O. (1994): The Economics of Pensions and Variable Retirement Schemes, New York, Wiley.

GRUBER, J. and WISE, D. A., eds. (1999): Social Security and Retirement Program Around the World, Chicago, Chicago University Press. 
MIRRLEES, J. A. (1971): "An Exploration in the Theory of Optimum Income Taxation", Review of Economic Studies 38 175-208.

ROTHSCHILD, M. and STIGLITZ, J. E. (1976): "Equilibrium in Competitive Insurance Markets: An Essay in the Economics of Imperfect Information", Quarterly Journal of Economics 80 629-649.

SHESHINSKI, E. (2004): "Optimal Delayed Retirement Credit", CESinfo Conference on Strategies for Reforming Pension Schemes, 5-6 November, 2004, Munich.

SIMONOVITS, A. (2003): "Designing Optimal Linear Rules for Flexible Retirement", Journal of Pension Economics and Finance 2 273-293.

SMITH, V. K., TAYLOR, D.H. and SLOAN, F. A. (2001): "Longevity Expectations and Death, Can People Predict Their Own Demise?" American Economic Review $911126-1134$.

VALDÉS-PRIETO, S. (2000): "The Financial Stability of Notional Account Pensions", Scandinavian Journal of Economics 102 395-417.

WALDRON, H. (2001): "Links between Early Retirement and Mortality", ORES Working Paper 93, Division of Economic Research, SS Administration.

WORLD BANK (1994): Averting the Old-Age Crisis, New York, N.Y., Oxford University Press. 
Fig.1. Fair second-best

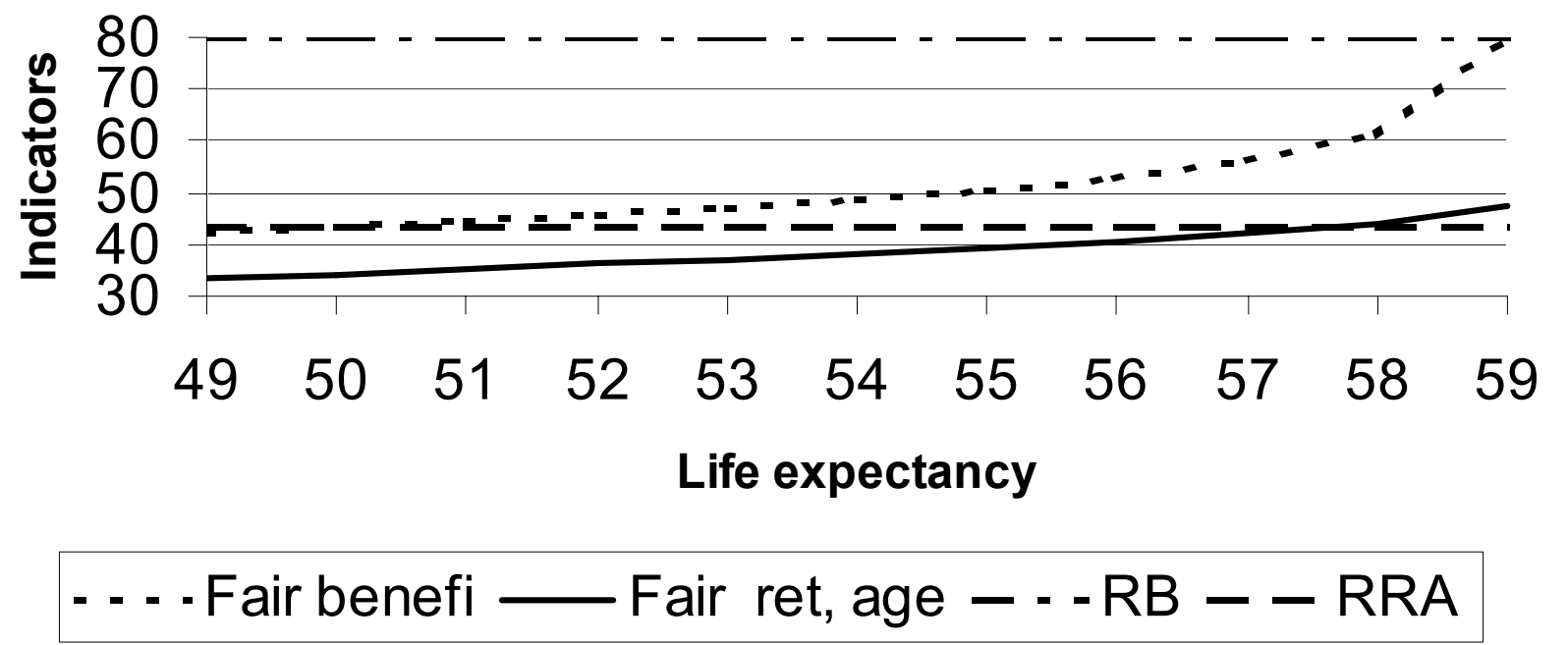

Fig. 2. Pareto-dominance

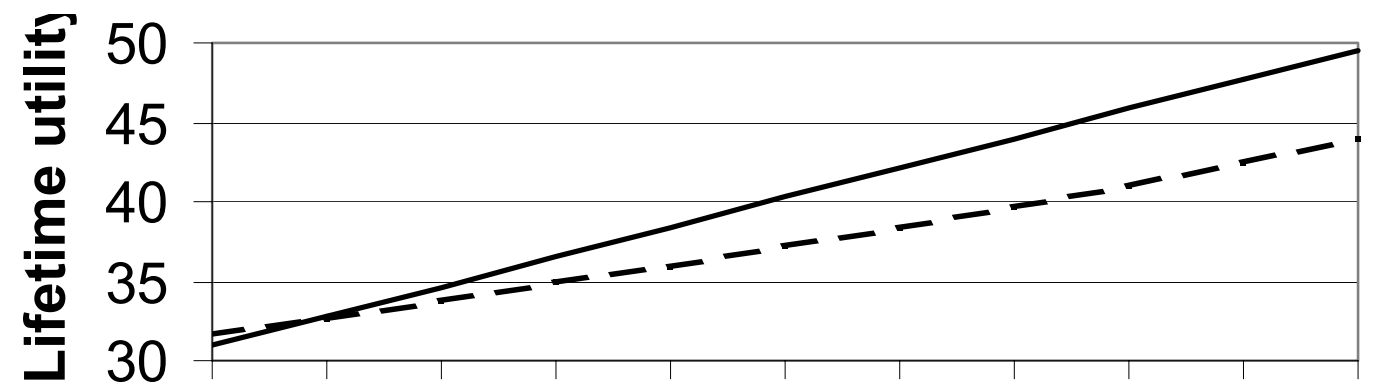

$\begin{array}{lllllllllll}49 & 50 & 51 & 52 & 53 & 54 & 55 & 56 & 57 & 58 & 59\end{array}$

Life expectancy

- - Fair — Redistributive 


\section{CESifo Working Paper Series}

(for full list see www.cesifo.de)

1305 Julia Darby, Anton Muscatelli and Graeme Roy, Fiscal Federalism, Fiscal Consolidations and Cuts in Central Government Grants: Evidence from an Event Study, October 2004

1306 Michael Waldman, Antitrust Perspectives for Durable-Goods Markets, October 2004

1307 Josef Honerkamp, Stefan Moog and Bernd Raffelhüschen, Earlier or Later: A General Equilibrium Analysis of Bringing Forward an Already Announced Tax Reform, October 2004

1308 M. Hashem Pesaran, A Pair-Wise Approach to Testing for Output and Growth Convergence, October 2004

1309 John Bishop and Ferran Mane, Educational Reform and Disadvantaged Students: Are They Better Off or Worse Off?, October 2004

1310 Alfredo Schclarek, Consumption and Keynesian Fiscal Policy, October 2004

1311 Wolfram F. Richter, Efficiency Effects of Tax Deductions for Work-Related Expenses, October 2004

1312 Franco Mariuzzo, Patrick Paul Walsh and Ciara Whelan, EU Merger Control in Differentiated Product Industries, October 2004

1313 Kurt Schmidheiny, Income Segregation and Local Progressive Taxation: Empirical Evidence from Switzerland, October 2004

1314 David S. Evans, Andrei Hagiu and Richard Schmalensee, A Survey of the Economic Role of Software Platforms in Computer-Based Industries, October 2004

1315 Frank Riedel and Elmar Wolfstetter, Immediate Demand Reduction in Simultaneous Ascending Bid Auctions, October 2004

1316 Patricia Crifo and Jean-Louis Rullière, Incentives and Anonymity Principle: Crowding Out Toward Users, October 2004

1317 Attila Ambrus and Rossella Argenziano, Network Markets and Consumers Coordination, October 2004

1318 Margarita Katsimi and Thomas Moutos, Monopoly, Inequality and Redistribution Via the Public Provision of Private Goods, October 2004

1319 Jens Josephson and Karl Wärneryd, Long-Run Selection and the Work Ethic, October 2004 
1320 Jan K. Brueckner and Oleg Smirnov, Workings of the Melting Pot: Social Networks and the Evolution of Population Attributes, October 2004

1321 Thomas Fuchs and Ludger Wößmann, Computers and Student Learning: Bivariate and Multivariate Evidence on the Availability and Use of Computers at Home and at School, November 2004

1322 Alberto Bisin, Piero Gottardi and Adriano A. Rampini, Managerial Hedging and Portfolio Monitoring, November 2004

1323 Cecilia García-Peñalosa and Jean-François Wen, Redistribution and Occupational Choice in a Schumpeterian Growth Model, November 2004

1324 William Martin and Robert Rowthorn, Will Stability Last?, November 2004

1325 Jianpei Li and Elmar Wolfstetter, Partnership Dissolution, Complementarity, and Investment Incentives, November 2004

1326 Hans Fehr, Sabine Jokisch and Laurence J. Kotlikoff, Fertility, Mortality, and the Developed World's Demographic Transition, November 2004

1327 Adam Elbourne and Jakob de Haan, Asymmetric Monetary Transmission in EMU: The Robustness of VAR Conclusions and Cecchetti's Legal Family Theory, November 2004

1328 Karel-Jan Alsem, Steven Brakman, Lex Hoogduin and Gerard Kuper, The Impact of Newspapers on Consumer Confidence: Does Spin Bias Exist?, November 2004

1329 Chiona Balfoussia and Mike Wickens, Macroeconomic Sources of Risk in the Term Structure, November 2004

1330 Ludger Wößmann, The Effect Heterogeneity of Central Exams: Evidence from TIMSS, TIMSS-Repeat and PISA, November 2004

1331 M. Hashem Pesaran, Estimation and Inference in Large Heterogeneous Panels with a Multifactor Error Structure, November 2004

1332 Maarten C. W. Janssen, José Luis Moraga-González and Matthijs R. Wildenbeest, A Note on Costly Sequential Search and Oligopoly Pricing, November 2004

1333 Martin Peitz and Patrick Waelbroeck, An Economist's Guide to Digital Music, November 2004

1334 Biswa N. Bhattacharyay and Prabir De, Promotion of Trade, Investment and Infrastructure Development between China and India: The Case of Southwest China and East and Northeast India, November 2004

1335 Lutz Hendricks, Why Does Educational Attainment Differ Across U.S. States?, November 2004

1336 Jay Pil Choi, Antitrust Analysis of Tying Arrangements, November 2004 
1337 Rafael Lalive, Jan C. van Ours and Josef Zweimueller, How Changes in Financial Incentives Affect the Duration of Unemployment, November 2004

1338 Robert Woods, Fiscal Stabilisation and EMU, November 2004

1339 Rainald Borck and Matthias Wrede, Political Economy of Commuting Subsidies, November 2004

1340 Marcel Gérard, Combining Dutch Presumptive Capital Income Tax and US Qualified Intermediaries to Set Forth a New System of International Savings Taxation, November 2004

1341 Bruno S. Frey, Simon Luechinger and Alois Stutzer, Calculating Tragedy: Assessing the Costs of Terrorism, November 2004

1342 Johannes Becker and Clemens Fuest, A Backward Looking Measure of the Effective Marginal Tax Burden on Investment, November 2004

1343 Heikki Kauppi, Erkki Koskela and Rune Stenbacka, Equilibrium Unemployment and Capital Intensity Under Product and Labor Market Imperfections, November 2004

1344 Helge Berger and Till Müller, How Should Large and Small Countries Be Represented in a Currency Union?, November 2004

1345 Bruno Jullien, Two-Sided Markets and Electronic Intermediaries, November 2004

1346 Wolfgang Eggert and Martin Kolmar, Contests with Size Effects, December 2004

1347 Stefan Napel and Mika Widgrén, The Inter-Institutional Distribution of Power in EU Codecision, December 2004

1348 Yin-Wong Cheung and Ulf G. Erlandsson, Exchange Rates and Markov Switching Dynamics, December 2004

1349 Hartmut Egger and Peter Egger, Outsourcing and Trade in a Spatial World, December 2004

1350 Paul Belleflamme and Pierre M. Picard, Piracy and Competition, December 2004

1351 Jon Strand, Public-Good Valuation and Intrafamily Allocation, December 2004

1352 Michael Berlemann, Marcus Dittrich and Gunther Markwardt, The Value of NonBinding Announcements in Public Goods Experiments: Some Theory and Experimental Evidence, December 2004

1353 Camille Cornand and Frank Heinemann, Optimal Degree of Public Information Dissemination, December 2004

1354 Matteo Governatori and Sylvester Eijffinger, Fiscal and Monetary Interaction: The Role of Asymmetries of the Stability and Growth Pact in EMU, December 2004 
1355 Fred Ramb and Alfons J. Weichenrieder, Taxes and the Financial Structure of German Inward FDI, December 2004

1356 José Luis Moraga-González and Jean-Marie Viaene, Dumping in Developing and Transition Economies, December 2004

1357 Peter Friedrich, Anita Kaltschütz and Chang Woon Nam, Significance and Determination of Fees for Municipal Finance, December 2004

1358 M. Hashem Pesaran and Paolo Zaffaroni, Model Averaging and Value-at-Risk Based Evaluation of Large Multi Asset Volatility Models for Risk Management, December 2004

1359 Fwu-Ranq Chang, Optimal Growth and Impatience: A Phase Diagram Analysis, December 2004

1360 Elise S. Brezis and François Crouzet, The Role of Higher Education Institutions: Recruitment of Elites and Economic Growth, December 2004

1361 B. Gabriela Mundaca and Jon Strand, A Risk Allocation Approach to Optimal Exchange Rate Policy, December 2004

1362 Christa Hainz, Quality of Institutions, Credit Markets and Bankruptcy, December 2004

1363 Jerome L. Stein, Optimal Debt and Equilibrium Exchange Rates in a Stochastic Environment: an Overview, December 2004

1364 Frank Heinemann, Rosemarie Nagel and Peter Ockenfels, Measuring Strategic Uncertainty in Coordination Games, December 2004

1365 José Luis Moraga-González and Jean-Marie Viaene, Anti-Dumping, Intra-Industry Trade and Quality Reversals, December 2004

1366 Harry Grubert, Tax Credits, Source Rules, Trade and Electronic Commerce: Behavioral Margins and the Design of International Tax Systems, December 2004

1367 Hans-Werner Sinn, EU Enlargement, Migration and the New Constitution, December 2004

1368 Josef Falkinger, Noncooperative Support of Public Norm Enforcement in Large Societies, December 2004

1369 Panu Poutvaara, Public Education in an Integrated Europe: Studying to Migrate and Teaching to Stay?, December 2004

1370 András Simonovits, Designing Benefit Rules for Flexible Retirement with or without Redistribution, December 2004 